\title{
Head and Neck Arteriovenous Malformations: Results of Ethanol Sclerotherapy
}

\author{
J. Pekkola, K. Lappalainen, P. Vuola, T. Klockars, P. Salminen, and A. Pitkäranta
}

\begin{abstract}
BACKGROUND AND PURPOSE: Peripheral AVM is a locally aggressive disease with a high tendency to recur; its treatment is complex, especially in the anatomically delicate head and neck area. Here, we report results of ethanol sclerotherapy for head and neck AVM and discuss its potential use for peripheral AVM.
\end{abstract}

MATERIALS AND METHODS: We retrospectively assessed degree of AVM eradication, complications, and clinical or imaging signs of recurrence for 19 patients treated with ethanol sclerotherapy for head and neck AVM (1 intraosseous, 18 soft-tissue AVMs).

RESULTS: Of the 19 patients, 11 had complete eradication of arteriovenous shunting at DSA, with 1 recurrence (mean follow-up 15 months), and for 7 patients, treatment is ongoing. During 59 treatment sessions, 12 patients experienced 14 complications, 1 leading to permanent functional damage.

CONCLUSIONS: Ethanol sclerotherapy has potential for complete eradication of head and neck AVM with low recurrence within the first year after completion of treatment. Complete eradication may require several treatment sessions during which complications should be minimized with careful techniques.

ABBREVIATIONS: $\mathrm{ECA}=$ external carotid artery; $n-\mathrm{BCA}=n$-butyl cyanoacrylate; $\mathrm{PVA}=$ polyvinyl alcohol particles

A VM is a congenital vascular malformation with direct communication from arteries to veins (arteriovenous shunting) and lack of a normal capillary network; the area with abnormal vasculature and shunting is called the nidus. ${ }^{1}$ The behavior of peripheral (extracranial) AVM is locally aggressive. Typically during puberty or adolescence, the initially quiescent lesion progresses to an expansive mass with cosmetic and functional disturbance. $^{2-5}$ With later progression, the AVM destroys normal tissues and eventually leads to complications such as severe disfigurement, uncontrollable bleeding, ulceration, pain, and cardiac volume overload. ${ }^{2-5}$

According to current knowledge, the only curative treatment for AVM is complete removal or ablation of the nidus, with recommended surgical treatment being complete radical resection. ${ }^{2-5}$ Radically resecting a vascular mass that may infiltrate nor-

Received December 30, 2011; accepted after revision March 27, 2012.

From the Department of Radiology (J.P., K.L.), University of Helsinki and HUS Radiology (Medical Imaging Center), Helsinki, Finland and Departments of Plastic Surgery (P.V.), Otorhinolaryngology (T.K., A.P.), and Pediatric Surgery (P.S.), Helsinki University Hospital, Helsinki, Finland.

Please address correspondence to Johanna Pekkola, HUS Radiology (Medical Imaging Center), P.O. Box 340, 00029HUS, Helsinki, Finland; e-mail: johanna. pekkola@hus.fi

http://dx.doi.org/10.3174/ajnr.A3180 mal structures in several tissue planes can, however, be very difficult and result in disfigurement and functional damage; this is especially true in the head and neck region. A recent series of 272 head and neck AVM patients ${ }^{2}$ demonstrates the difficulty of achieving a cure for peripheral AVM: it reports an $81 \%$ recurrence rate after surgical resection and 98\% after embolization. Suggested recurrence mechanisms include a proangiogenetic environment involving hypoxia, trauma, and inflammation, ${ }^{2}$ and recanalization of the nidus vasculature. ${ }^{2,6-8}$ If any nidus remnant remains, these factors will lead to a recurrence, often with complex architecture and extensive vascular recruitment.

The term "embolization" in the AVM literature refers to several different approaches: blocking the vascular bed or feeding arteries or both with particulate agents, gelatin pledgets, coils, or liquid embolic materials. The goal may be facilitating subsequent surgery or long-term control of the AVM by complete embolization. Absolute ethanol differs from other liquid embolics, being a toxic substance that permanently destroys the endothelial cells and the vessel wall, ${ }^{9}$ and careful nidus ablation with endovascular ethanol (ethanol sclerotherapy) has potential for angiographic eradication of extracranial AVMs. ${ }^{10-16}$ Empirical evidence concerning whether ethanol sclerotherapy can offer more lasting long-term results than careful embolization with other liquid 
agents is, however, lacking. Further, the complication risk due to its toxic nature warrants caution.

Ethanol sclerotherapy of head and neck AVM is challenging due to the delicate anatomy, and descriptions of its results are infrequent. To our knowledge, only 3 studies ${ }^{17-19}$ report on ethanol sclerotherapy for head and neck soft-tissue AVMs, with $2^{18,19}$ describing follow-up longer than the immediate postprocedure period. One additional article reports ethanol sclerotherapy results for intraosseous maxillary or mandibular AVM, ${ }^{20}$ possibly a diverse subset of AVMs.

Our aim is to report immediate treatment results, complications, and currently available follow-up information for 19 patients with head and neck AVMs treated with ethanol sclerotherapy (18 with soft tissue AVMs, 1 with bone involvement), and discuss potential use of ethanol sclerotherapy for peripheral AVM.

\section{MATERIALS AND METHODS Literature Review}

For an overview of the literature, we conducted an Ovid Medline search with the following keyword combinations: "arteriovenous malformation" AND "head and neck"; "arteriovenous malformation" AND "therapeutic embolization"; and "arteriovenous malformation" AND "ethanol/alcohol ablation.” We limited searches to articles in English published during 1991-2011 with an abstract available through Ovid Medline, discarding those on conditions other than congenital AVM or reporting no treatment results.

\section{Patients}

For this retrospective study, we used our radiology information system to identify all 19 patients treated with ethanol sclerotherapy for head and neck AVM between January 1, 2007, and September 30, 2011, at our institution (a tertiary referral center providing specialist-level health care for approximately 1.5 million people, with a multidisciplinary team for vascular anomaly patients). The study was accepted by the institutional ethics committee.

With chart review, we recorded AVM localization, clinical symptoms, clinical stage according to the Schöbinger staging system (Table 1), all treatments before current ethanol sclerotherapy, number and techniques of sclerotherapy sessions, and complications resulting from sclerotherapy. Two interventional radiologists reviewed all pre- and posttreatment DSA angiograms and determined the AVM angioarchitectural type according to Cho et $\mathrm{al}^{21}$ in the pretreatment DSA, and degree of arteriovenous shunt eradication (complete or partial) in the posttreatment DSA. To explore for clinical or imaging signs of recurrence after ethanol sclerotherapy, we reviewed documents covering all follow-up clinical appointments and reports and any posttreatment MR imaging or DSA studies. We considered reappearance of a mass or pulsation, or both, as clinical signs of recurrence. Reappearance of a mass or of flow voids, or both (MR imaging), or indication of arteriovenous shunting (DSA or time-resolved MR imaging) were imaging signs of recurrence.
Table 1: Schöbinger classification of arteriovenous malformations ${ }^{4}$

\begin{tabular}{ll}
\hline \multicolumn{1}{c}{ Stage } & \multicolumn{1}{c}{ Clinical Symptoms } \\
\hline I (Quiescence) & Skin warmth, discoloration \\
II (Expansion) & Enlargement, pulsation, bruit \\
III (Destruction) & Pain, ulceration, bleeding \\
IV (Decompensation) & Cardiac failure due to volume overload \\
\hline
\end{tabular}

\section{Ethanol Sclerotherapy}

All procedures necessitate general anesthesia because ethanol injections are painful and the procedures lengthy. We do not routinely monitor pulmonary artery pressure but do so for treatment of high-flow lesions and anticipated high volumes of ethanol.

We advance a microcatheter selectively to the nidus with coaxial techniques from femoral access. After reaching the nidus, we check that no branches supplying normal tissues will visualize during contrast injection through the microcatheter (Fig 1). If the $\mathrm{AVM}$ is near to or affecting the skin or mucosal surfaces, we observe whether saline injection through the microcatheter causes either one to blanch: if so, ethanol injection at that position will lead to distribution of ethanol to the skin or to the mucosal surface and thus to necrosis. This necessitates repositioning the catheter. If we cannot reach the nidus selectively via an intra-arterial route (for instance, with recurrent lesions with tortuous small-caliber feeding arteries or proximal ligations), we use percutaneous needle puncture to the nidus and apply the same precautions before ethanol injections as with intra-arterial access.

With high-flow shunting, we may compress the venous outflow during ethanol injection; in these cases, we also do the test injections with outflow compression. In selected cases, we use $n$-BCA or Onyx (ev3, Irvine, California) or mechanical occlusion of the venous return with coils or balloons to reduce blood flow through the lesion before ethanol injections.

Ethanol is not visualized with $\mathrm{x}$-rays, and the operator has to test volume and rate of ethanol injection with contrast injections to determine the appropriate injection needed to fill the nidus. In most cases, we use ethanol 95\%; with diffuse lesions affecting the skin or mucosal surfaces, we may use ethanol $95 \%$ diluted with saline to $50 \%$.

After ethanol injection, we wait 5-10 minutes and then inject contrast through the microcatheter to see whether arteriovenous shunting has ceased and whether any collateral arteries to normal tissues are now visible. If shunting remains, and the catheter position remains acceptable, we repeat the ethanol injection. After shunting through one vascular pedicle has ceased, we change the microcatheter position to a new pedicle as long as shunting is visible in any less-selective DSA run.

We typically discharge the patient on the same or the following day. Posttreatment swelling lasts 1 to several days; it is rarely painful, and if so, any pain is controllable with nonsteroidal antiinflammatory medication. To reduce swelling, we administer IV dexamethasone $(5-10 \mathrm{mg}$ ) during the procedure and continue with diminishing doses of oral methylprednisolone 4-6 days postprocedure. We usually cannot eradicate all arteriovenous shunting during 1 session, and intraprocedural swelling and thrombosis can cover some residual that will recanalize later. This proves true especially with extensive or architecturally complex lesions. We therefore schedule successive treatments at 2- to 

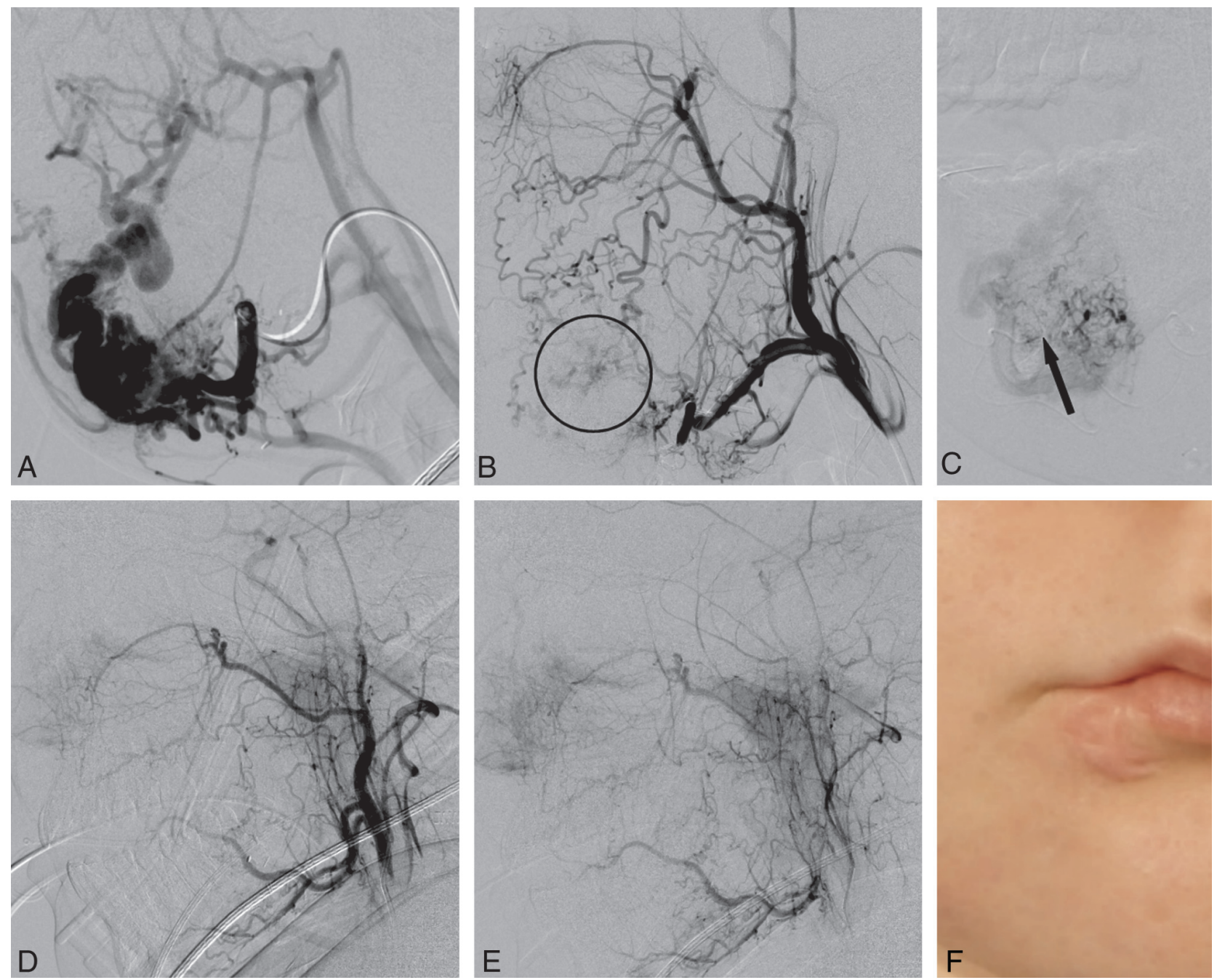

FIG 1. Pre- and posttreatment DSA and clinical photo of patient 1. Presclerotherapy DSA $(A)$ shows a high-flow AVM with most of the arterial flow from still-patent proximal facial artery branches. A right ECA angiogram after 1 sclerotherapy session (B) shows a small nidus remnant (circled) with feeders from right facial and internal maxillary arteries through tortuous small-caliber vessels. This was treated during 2 subsequent sessions via intra-arterial and direct puncture access. A microcatheter angiogram through a peripheral right facial artery branch (C) exemplifies a selective access to the nidus, with visualization of only pathologic nidal arteries and outflow veins; an arrow marks the microcatheter tip. Right ECA angiogram 4 months after sclerotherapy completion (early arterial phase, $D$; late arterial phase, $E$ ) shows no arteriovenous shunting or pathologic vasculature, and the tortuous feeders from the internal maxillary artery have regressed. A clinical photo $(F)$ shows a scar resulting from a skin necrosis during the second treatment.

4-month intervals until shunting is eradicated, and perform 1 DSA under general anesthesia 4-12 months after apparent eradication. At this checkup DSA, we take care to examine all vascular pedicles that could feed the possible residual or recurrence and treat any detected residual at the same time. After completed sclerotherapy, all patients undergo clinical and MR imaging followup; the follow-up schedule depends on anticipated recurrence risk. The follow-up MR imaging includes standard sequences, gadolinium-enhanced images, and time-resolved MRA.

\section{RESULTS}

\section{Situation before Sclerotherapy}

All patients presented with Schöbinger stage II or III (for patient characteristics, see Table 2). Of the 19 patients, 18 had soft-tissue AVMs, all of types IIIa or IIIb according to Cho et al. ${ }^{21}$ One (patient 13) had maxillary intraosseous AVM with a dominant outflow vein and dilated venous pouch; he, however, also had a more diffuse part of the nidus that drained to several smaller-caliber veins. Of the 19 patients, 12 had had prior surgical resections (1-6 per patient; mean, 3 ) with or without preoperative embolizations, 11 with initial diagnosis other than AVM; 9 had had palliative PVA embolizations; and 5 had proximal ligations of the feeding arteries. One had had coiling of the feeding arteries and directpuncture ethanol sclerotherapy in a referring institution, resulting in tissue necrosis and resection. The multidisciplinary team referred all patients to endovascular treatment because the lesion was either widespread, very diffuse, or traversed several tissue planes; complete surgical resection was considered very difficult or included major risks for complications or disfigurement.

\section{Treatment Techniques}

Of the 19, 18 patients received ethanol sclerotherapy via an intraarterial route, and 8 additionally or solely via direct puncture. Number of sessions per patient ranged from 1-6 (mean, 3.1). The 
Table 2: Patient characteristics

\begin{tabular}{|c|c|c|c|c|c|}
\hline Patient & $M / F / A g e^{a}$ & AVM Localization & $\begin{array}{l}\text { Previous } \\
\text { Treatments }\end{array}$ & Symptoms & $\begin{array}{l}\text { Schöbinger } \\
\text { Stage }\end{array}$ \\
\hline 1 & $\mathrm{~F} / 17$ & Cheek, submandibular area & $1,2,4$ & Regrowth, pulsating mass & II \\
\hline 2 & $\mathrm{~F} / 20$ & Nose ala, nasion, periorbital & $1,4^{\mathrm{b}}$ & Regrowth, pulsating mass & ॥ \\
\hline 3 & $F / 23$ & Auricle & $1,3,4,5$ & Regrowth, pulsating mass, pain & III \\
\hline 4 & $M / 30$ & Mid- and lower face, lower lip & $1,2,3,4$ & Regrowth, pulsating mass, ulceration & III \\
\hline 5 & $M / 12$ & Upper lip & 1 & Regrowth, mass & ॥ \\
\hline 6 & $\mathrm{~F} / 42$ & Tongue & No & Growing pulsating mass, pain, bleeding & III \\
\hline 7 & $\mathrm{~F} / 33$ & Auricle, scalp & $1,3,4^{b}$ & Regrowth, pulsating mass, tissue destruction & III \\
\hline 8 & $M / 30$ & Midface, upper lip & 1,4 & Regrowth, pain, epistaxis, ulceration & III \\
\hline 9 & $\mathrm{~F} / 15$ & Lower lip & 2,4 & Regrowth, pulsating mass & II \\
\hline 10 & $F / 46$ & Occipital scalp & No & Growing pulsating mass, pain & III \\
\hline 11 & $\mathrm{~F} / 17$ & Occipital scalp & No & Growing pulsating mass & ॥ \\
\hline 12 & $M / 47$ & Midface, skull base, periorbital & $1,2,3,4^{b}$ & Recurrent severe epistaxis & III \\
\hline 13 & $M / 19$ & Maxilla, intraosseal & No & Growing pulsating mass & II \\
\hline 14 & $M / 38$ & Tongue, floor of the mouth, chin, lips & No & Growing pulsating mass & ॥ \\
\hline 15 & $\mathrm{~F} / 13$ & Tongue, floor of the mouth, chin, lower lip & 1 & Regrowth, pulsating mass & II \\
\hline 16 & $M / 6$ & Upper lip & No & Growing mass & ॥ \\
\hline 17 & $\mathrm{~F} / 6$ & Upper lip & No & Growing mass & ॥ \\
\hline 18 & $\mathrm{~F} / 25$ & Midface, upper lip & $1,2,4$ & Regrowth, bleeding & III \\
\hline 19 & $\mathrm{~F} / 25$ & Midface, upper lip, periorbital & 1,4 & Regrowth, bleeding & III \\
\hline
\end{tabular}

Note:-Previous treatments: $1=$ local resection; $2=$ resection with radical aim; $3=$ proximal artery ligation; $4=$ PVA embolization; $5=$ ethanol sclerotherapy.

a Age at the beginning of current sclerotherapies.

bICA supply after surgery.

Table 3: Response to ethanol sclerotherapies and follow-up information

\begin{tabular}{|c|c|c|c|c|c|c|}
\hline \multirow[b]{2}{*}{ Patient } & \multirow[b]{2}{*}{ Sclerotherapies } & \multirow{2}{*}{$\begin{array}{c}\text { Shunt } \\
\text { Eradication }\end{array}$} & \multirow[b]{2}{*}{ Symptoms } & \multicolumn{2}{|c|}{ Follow-Up (months) } & \multirow[b]{2}{*}{ Recurrence } \\
\hline & & & & Imaging & Clinical & \\
\hline 1 & 3 & Complete & Resolved & 15 & 15 & No \\
\hline 2 & 1 & Complete & Diminished & 7 & 24 & Yes \\
\hline 3 & 4 & Complete & Resolved & 13 & 12 & No \\
\hline 4 & 1 & Complete & Resolved & 7 & 30 & No \\
\hline 5 & 2 & Complete & Diminished & 3 & 11 & No \\
\hline 6 & 1 & Complete & Resolved & 11 & 11 & No \\
\hline 7 & 5 & Complete & Diminished & - & 6 & No \\
\hline 8 & 5 & Complete & Diminished & 12 & 12 & No \\
\hline 9 & 2 & Complete & Resolved & 5 & 5 & No \\
\hline 10 & 2 & Complete & Resolved & NA & NA & NA \\
\hline 11 & 1 & Complete & Resolved & NA & NA & NA \\
\hline 12 & 1 & Partial & Resolved ${ }^{a, b}$ & - & 7 & \\
\hline 13 & 4 & Partial & Resolved & Ongoing treatment & & \\
\hline 14 & 5 & Partial & Diminished & Ongoing treatment & & \\
\hline 15 & 6 & Partial & Unchanged & Ongoing treatment & & \\
\hline 16 & 4 & Partial & Diminished & Ongoing treatment & & \\
\hline 17 & 5 & Partial & Progression & Ongoing treatment & & \\
\hline 18 & 3 & Partial & Diminished & Ongoing treatment & & \\
\hline 19 & 4 & Partial & Diminished & Ongoing treatment & & \\
\hline
\end{tabular}

Note:-NA indicates recent treatments, no follow-up available.

${ }^{a}$ Later recurred.

${ }^{\mathrm{b}}$ Lesion never eradicated.

ethanol (95\%) volume per session was 0.25-48 mL (not exceeding $1 \mathrm{~mL} / \mathrm{kg}$ ) at single-injection doses of $0.25-3 \mathrm{~mL}$. We used $n$-BCA or Onyx in addition to ethanol for 6 patients, and occluded the dominant venous return with coils for 1 (patient 13). These were patients either with high-volume shunts or dominant outflow structures amenable to transvenous occlusion; we injected ethanol into the arterial side after reduction of flow through the lesion. Without flow reduction, ethanol would be less effective with its transmission to the venous side probably increasing systemic complication risk. For 1 (patient 12), we used gelatin pledgets in addition to intra-arterial ethanol in an attempt to control severe epistaxis. Patient 4 underwent a radical resection of an extensive mid-face AVM after 2 preoperative PVA embolizations and received 1 ethanol treatment for a small residual upper-lip nidus.

\section{Response to Sclerotherapy}

Posttreatment DSA showed complete angiographic eradication of arteriovenous shunting for 11 patients, all with relieved or diminished symptoms (Table 3). Of these patients, 6 had remaining diffuse hypervascularity in the last immediate posttreatment angiogram, but a repeat DSA at 2-15 months showed no re-emergence of the shunt. Residual symptoms included residual mass or tissue hypertrophy after long-standing disease (4 patients), glau- 
coma (1 patient), and chronic headache with unclear association with AVM (1 patient).

Of the 11 patients with complete eradication of arteriovenous shunting, 9 had postprocedure clinical follow-up (length 5-30 months; mean, 13) and 8 had imaging follow-up (length 3-15 months; mean, 9) with DSA or MR imaging or both. Pregnancy postponed imaging follow-up for patient 7 , and 2 with very recent treatments (patients 10 and 11) have, to date, not undergone the first follow-up visit with clinical status and posttreatment DSA. One of the 11 had a clinical relapse at 24 months (patient 2); the remaining patients with complete shunt eradication have shown no evidence of recurrence.

Treatments are ongoing for 7 patients, with the aim of achieving complete eradication with careful assessment of risks. Of these, patient 17 has had clinical progression during treatment. The symptoms of the remaining 6 have diminished or remained stable. One (patient 12) suffered a major complication during an attempt to control severe epistaxis. For him, further treatments are planned only if serious symptoms occur.

\section{Complications}

During 59 treatments, we caused 14 complications in 12 patients: 13 were due to ethanol injections and 1 due to femoral access. The most common complication was local skin (5 patients, 1 patient twice) or mucosal necrosis (2 patients). Of the skin necroses, 2 required plastic correction, 2 were treated with antibiotics due to secondary infection, and 2 healed spontaneously; all eventually left a scar acceptable to the patient and necessitating no further correction (Fig 1). One mucosal necrosis healed completely, and 1 without functional damage but with loss of lower-lid eyelashes. One patient, during treatment of an extensive scalp AVM, had local loss of hair without necrosis of the underlying skin.

Two patients had local tissue necrosis (other than skin or mucosa), 1 superficially at the side of the tongue and 1 in the masseter muscle; both healed with no functional disturbance. One patient, after treatment of a medial canthus AVM, developed Horner syndrome, and 1 had femoral access-site hematoma; both resolved spontaneously within days. One complication led to severe functional damage (nearly complete loss of sight in the only remaining eye; the other eye had been enucleated earlier). This happened during an attempt to control severe epistaxis refractory to other treatments due to a mid-face AVM with arterial recruitment through the skull base and possibly abnormal retinal supply, and the probable mechanism was retinal ischemia. Apart from this, no complications caused permanent functional damage.

\section{DISCUSSION}

Head and neck AVM is a locally aggressive lesion in a delicate anatomic region and tends to recur after interventions. ${ }^{2-5}$ Our results suggest that ethanol sclerotherapy may have potential as a treatment technique for head and neck AVM, but should be implemented very carefully due to the risk for complications. The most important factors in assessing the usability of any treatment method for peripheral AVM are its success in complete nidus eradication, complication rate, and long-term recurrence rate.

Reports on ethanol sclerotherapy of trunk and extremity AVMs have shown potential for total nidus ablation ${ }^{10-16}$; success is, however, less for lesions in delicate locations such as the hand and fingers. ${ }^{16}$ The diagnosis "AVM" possibly includes subsets with diverse biologic behavior, and lesion angioarchitecture may predict response to treatments. For example, AVMs with a dilated venous fistula within the mandible or maxilla may respond to several approaches that target the intraosseous venous structure ${ }^{20,22-26}$; soft-tissue lesions with diffuse architecture are the most difficult to treat. ${ }^{21}$ For the head and neck area, 2 studies on auricular AVMs report success rates for complete nidus devascularization of $18 \%{ }^{18}$ and $75 \% .{ }^{19}$ Interpreting these percentages is difficult, because some proportion of the treatments in all series is still ongoing, and the reported material limited. Jeong and coauthors ${ }^{17}$ report a $50 \%$ success rate for ethanol sclerotherapy of head and neck soft-tissue AVMs in a series in which treatment technique was changed to surgery if the AVM did not decrease to $<50 \%$ after 3 sclerotherapy sessions; this series included neither Schöbinger stage III patients nor AVMs with multiple large shunts.

In our series, of the 19 patients with head and neck AVMs at Schöbinger stage II-III, 11 had complete eradication of arteriovenous shunting. For 7 , treatments are ongoing, and for 1 , the treatment failed. Taking into account the difficulty of reaching radicality for extensive head and neck AVMs by any current method, we consider these results promising. Of the patients with ongoing treatment, 1 had clinical progression during treatment; her treatments were at that time postponed after a skin/mucosal complication. Acknowledging the potential of AVM stimulation by partial treatments, this has to be considered seriously. With ethanol sclerotherapy, several successive treatments are often the rule and every treatment carries a complication risk. The patient should be carefully informed about this before start of treatment, and the treatments must be completed with meticulous techniques to avoid complications.

With angiographic guidance, assessment of nidus ablation relies on direct observation of abnormal vasculature and arteriovenous shunting. This differs from surgical resection, where careful preplanning, observation of bleeding patterns at resection surfaces, and intraprocedural Doppler sonography determine procedural radicality. ${ }^{2}$ In theory, angiographic guidance should facilitate eradication of the whole nidus, and be of aid especially with extensive lesions traversing several tissue planes with difficult surgical access. Here, it is important to carefully assess any residual AVM with selective injections into all vascular pedicles that could anatomically supply the AVM. In staged embolization of complex AVMs, ethanol has one important asset: its invisibility. In contrast to other liquid agents, it does not leave a radiopaque cast that would complicate the technical challenges of every successive embolization.

Although most complications from ethanol sclerotherapy heal without long-standing functional damage, a serious risk remains for permanent or major complications, reported at $0 \%-26 \%$ frequency per patient. ${ }^{10-20}$ Direct interpretation of these figures is difficult because classification of complications between series differs. For example, some include in major complications any event that requires hospitalization for $>48$ hours, including those that resolve completely with or without treatment, ${ }^{14}$ while others may record as major complications only events that leave a per- 
manent disturbance. Ethanol injection into arterial branches that supply normal tissues will always cause tissue destruction. Such complications can be minimized with highly selective access to the nidus and knowledge of the relevant vascular anatomy ${ }^{27,28}$; this is especially important in the head and neck region, with potentially very serious complications due to ECA-ICA anastomoses and ECA supply to cranial nerves. ${ }^{29}$ The most common complication of ethanol sclerotherapy is local skin or mucosal surface necrosis. ${ }^{10-20}$ These should be minimized with careful technique, but completely avoiding them may be impossible if the AVM itself affects the skin or mucosal surfaces.

Sudden severe cardiovascular collapse is a rare complication of ethanol sclerotherapy for vascular malformations. ${ }^{1,30-33}$ Its mechanism is unknown: suppressed cardiac conductivity and precapillary pulmonary artery spasm have been suggested, and 1 case is documented with acute lung capillitis/vasculitis. ${ }^{32}$ Transient pulmonary artery pressure rises occur immediately after ethanol injection and during recovery, ${ }^{32-34}$ but their relationship to the risk for cardiovascular collapse is unclear. ${ }^{32}$ Many interventionalists limit the maximum ethanol dose per session to $0.8-1$ $\mathrm{mL} / \mathrm{kg}$, because greater doses raise plasma levels above $80 \mathrm{mg} /$ dL. ${ }^{35,36}$ This does not, however, offer protection from the risk of cardiovascular collapse ${ }^{32}$; instead, single-injection doses may be more relevant. ${ }^{37}$ Other possible systemic effects of ethanol include intravascular hemolysis ${ }^{38}$ and bronchospasm. ${ }^{39}$

Our complication rate was in line with rates in other studies. ${ }^{10-20}$ All permanently visible complications included scarring after skin necrosis $(n=5)$ and local loss of cutaneous hair $(n=2)$. In retrospect, 3 of our skin/mucosal complications ( 1 in an upper lip, 1 in a lower eyelid, 1 in a scalp) probably resulted from an injection not sufficiently selective during treatment of a superficial AVM and might have been avoidable. Results for the 3 patients with periorbital AVMs in our population warrant specific discussion. For 1 patient (patient 19), we could find no route for any embolization to the periorbital component. She was later assigned to surgery. One (patient 2) we treated with direct puncture ethanol sclerotherapy; the access was to a small venous structure that collected the arterial inflow and drained into external facial and superior ophtalmic veins. She had transient Horner syndrome, despite compression of the cavernous sinus outflow during the procedure. One (patient 12) suffered a serious complication (near complete blindness in the only eye) during an attempt to control severe epistaxis in a high-risk situation, with periorbital AVM involvement. These results stress that using a toxic substance in the periorbital area may be a high complication risk and should be done only with extreme caution.

Most AVM recurrences manifest within the first year after intervention, but a minimum of 5 years of follow-up is necessary to assess long-term control. ${ }^{2}$ The follow-up periods in ethanol sclerotherapy case series vary; most report a follow-up of 1-2 years for most of the completely eradicated lesions with no recurrences, ${ }^{11,13-16,19}$ but for all series, the follow-up is less than 5 years. Our data document only the immediate and short-term efficacy of ethanol sclerotherapy in a reasonable-sized cohort of head and neck AVMs, and provide no information on AVM recurrence in the intermediate or long term. Based on experience with ethanol embolization of AVMs throughout the body and the lack of pub- lished long-term reports, it is likely that a portion of the lesions will recur.

Other limitations of the study include its retrospective nature. This is, in part, balanced by the fact that our center is the only one to provide specialist-level AVM care for a known population (1.5 million people), and we additionally receive patients with difficult AVMs as referrals from a larger population base of 5.4 million. This means that loss from follow-up is minimal, and we will very likely see not only the successful treatment results but also patients with recurrences and failed treatments.

It is clear that these patients require rigorous long-term follow-up, and we hope that early detection and treatment of recurrences will be possible. In the future, advances in understanding AVM pathophysiology will hopefully offer additional means to control difficult AVMs. ${ }^{40}$ The message of this study is that ethanol, as a potent but toxic agent, has a role in bringing even very difficult extracranial head and neck AVMs under control, but treatments should be completed with caution and appreciation of this delicate anatomy.

\section{CONCLUSIONS}

Carefully completed ethanol sclerotherapy has potential for complete angiographic eradication of even extensive head and neck AVMs. Meticulous techniques are necessary to avoid complications, and long-term follow-up is vital for assessing permanence of the results.

\section{ACKNOWLEDGMENTS}

We warmly thank Carol Norris for her aid in revising this manuscript.

\section{REFERENCES}

1. Young AE, Mulliken JB. Arteriovenous malformations. In: Mulliken JB, ed. Vascular Birthmarks: Haemangiomas and Malformations. Philadelphia: WB Saunders, 1988:228-45

2. Liu AS, Mulliken JB, Zurakowski D, et al. Extracranial arteriovenous malformations: natural progression and recurrence after treatment. Plast Reconstr Surg 2010;125:1185-94

3. Kohout MP, Hansen M, Pribaz JJ, et al. Arteriovenous malformations of the head and neck: natural history and management. Plast Reconstr Surg 1998;102:643-54

4. Bradley JP, Zide BM, Berenstein A, et al. Large arteriovenous malformations of the face: aesthetic results with recurrence control. Plast Reconstr Surg 1999;103:351-61

5. Wu JK, Bisdorff A, Gelbert F, et al. Auricular arteriovenous malformation: evaluation, management, and outcome. Plast Reconstr Surg 2005;115:985-95

6. Sure U, Battenberg E, Dempfle A, et al. Hypoxia-inducible factor and vascular endothelial growth factor are expressed more frequently in embolized than in nonembolized cerebral arteriovenous malformations. Neurosurgery 2004;55:663-69

7. Natarajan SK, Born D, Ghodke B, et al. Histopathological changes in brain arteriovenous malformations after embolization using Onyx or N-butyl cyanoacrylate. Laboratory investigation. J Neurosurg 2009;111:105-13

8. Standard SC, Guterman LR, Chavis TD, et al. Delayed recanalization of a cerebral arteriovenous malformation following angiographic obliteration with polyvinyl alcohol embolization. Surg Neurol 1995;44:109-12

9. Buchta K, Sands J, Rosenkrantz H, et al. Early mechanism of action of arterially infused alcohol U.S.P. in renal devitalization. Radiology 1982;145:45-48

AJNR Am J Neuroradiol 34:198-204 Jan 2013 www.ajnr.org 
10. Yakes WF, Haas DK, Parker SH, et al. Symptomatic vascular malformations: ethanol embolotherapy. Radiology 1989;170: 1059-66

11. Yakes WF, Luethke JM, Parker SH, et al. Ethanol embolization of vascular malformations. Radiographics 1990;10:787-96

12. Lee BB, Bergan JJ. Advanced management of congenital vascular malformations: a multidisciplinary approach. Cardiovasc Surg 2002;10:523-33

13. Do YS, Yakes WF, Shin SW, et al. Ethanol embolization of arteriovenous malformations: interim results. Radiology 2005;235:674-82

14. Cho SK, Do YS, Kim DI, et al. Peripheral arteriovenous malformations with a dominant outflow vein: results of ethanol embolization. Korean J Radiol 2008;9:258-67

15. Do YS, Park KB, Park HS, et al. Extremity arteriovenous malformations involving the bone: therapeutic outcomes of ethanol embolotherapy. J Vasc Interv Radiol 2010;21:807-16

16. Park HS, Do YS, Park KB, et al. Ethanol embolotherapy of hand arteriovenous malformations. J Vasc Surg 2011;53:725-31

17. Jeong HS, Baek CH, Son YI, et al. Treatment for extracranial arteriovenous malformations of the head and neck. Acta Otolaryngol 2006;126:295-300

18. Zheng LZ, Fan XD, Zheng JW, et al. Ethanol embolization of auricular arteriovenous malformations: preliminary results of 17 cases. AJNR Am J Neuroradiol 2009;30:1679-84

19. Jin YB, Lin $\mathrm{X}$, Chen $\mathrm{H}$, et al. Auricular arteriovenous malformations: potential success of superselective ethanol embolotherapy. J Vasc Interv Radiol 2009;20:736-43

20. Fan XD, Su LX, Zheng JW, et al. Ethanol embolization of arteriovenous malformations of the mandible. AJNR Am J Neuroradiol 2009;30:1178-83

21. Cho SK, Do YS, Shin SW, et al. Arteriovenous malformations of the body and extremities: analysis of therapeutic outcomes and approaches according to a modified angiographic classification. J Endovasc Ther 2006;13:527-38

22. Rodesch G, Soupre V, Vazquez MP, et al. Arteriovenous malformations of the dental arcades. The place of endovascular therapy: results in 12 cases are presented. J Craniomaxillofac Surg 1998;26: 306-13

23. Fan X, Zhang Z, Zhang C, et al. Direct-puncture embolization of intraosseous arteriovenous malformation of jaws. J Oral Maxillofac Surg 2002;60:890-96

24. Persky MS, Yoo HJ, Berenstein A. Management of vascular malformations of the mandible and maxilla. Laryngoscope 2003;113: 1885-92

25. Cohen JE, Gomori JM, Grigoriadis S, et al. Complete and persistent occlusion of arteriovenous malformations of the mandible after endovascular embolization. Neurol Res 2009;31:467-71

26. Liu D, Ma X, Zhao F, et al. Intraosseous embolotherapy of central arteriovenous malformations in the jaw: long-term experience with 8 cases. J Oral Maxillofac Surg 2009:67:2380-87

27. Yakes WF, Rossi P, Odink H. How I do it. Arteriovenous malformation management. Cardiovasc Intervent Radiol 1996;19:65-71

28. Do YS, Park KB, Cho SK. How do we treat arteriovenous malformations (tips and tricks)? Tech Vasc Interv Radiol 2007;10:291-98

29. Geibprasert S, Pongpech S, Armstrong D, et al. Dangerous extracranial-intracranial anastomoses and supply to the cranial nerves: vessels the neurointerventionalist needs to know. AJNR Am J Neuroradiol 2009;30:1459-68

30. Yakes WF, Krauth L, Ecklund J, et al. Ethanol endovascular management of brain arteriovenous malformations: initial results. Neurosurgery 1997;40:1145-52

31. Chapot R, Laurent A, Enroljas O, et al. Fatal cardiovascular collapse during ethanol sclerotherapy of a venous malformation. Interv Neuroradiol 2002;8:321-24

32. Mitchell SE, Shah AM, Schwengel D. Pulmonary artery pressure changes during ethanol embolization procedures to treat vascular malformations: can cardiovascular collapse be predicted? J Vasc Interv Radiol 2006;17:253-62

33. Shin BS, Do YS, Lee BB, et al. Multistage ethanol sclerotherapy of soft-tissue arteriovenous malformations: effect on pulmonary arterial pressure. Radiology 2005;235:1072-77

34. Ko JS, Kim CS, Shin BS, et al. Changes in pulmonary artery pressures during ethanol sclerotherapy for arteriovenous malformations: identifying the most vulnerable period. Clin Radiol 2011;66:639-44

35. Mason KP, Michna E, Zurakowski D, et al. Serum ethanol levels in children and adults after ethanol embolization or sclerotherapy for vascular anomalies. Radiology 2000;217:127-32

36. Lee JJ, Do YS, Kim JA. Serum ethanol levels after alcohol sclerotherapy of arteriovenous malformations. J Korean Med Sci 2004; 19:51-54

37. Ko JS, Kim JA, Do YS, et al. Prediction of the effect of injected ethanol on pulmonary arterial pressure during sclerotherapy of arteriovenous malformations; relationship with dose of ethanol. J Vasc Interv Radiol 2009;20:39-45

38. Behnia R. Systemic effects of absolute alcohol embolization in a patient with a congenital arteriovenous malformation of the lower extremity. Anesth Analg 1995;80:415-17

39. Stefanutto TB, Halback V. Bronchospasm precipitated by ethanol injection in arteriovenous malformation. AJNR Am J Neuroradiol 2003;24:2050-51

40. Burrows PE, Mulliken JB, Fishman SJ, et al. Pharmacological treatment of a diffuse arteriovenous malformation of the upper extremity in a child. J Craniofac Surg 2009;20:1629-30

41. Shöbinger R. In: Proceedings of International Society for the Study of Vascular Anomalies Congress; Rome, Italy, June 23-26,1996 